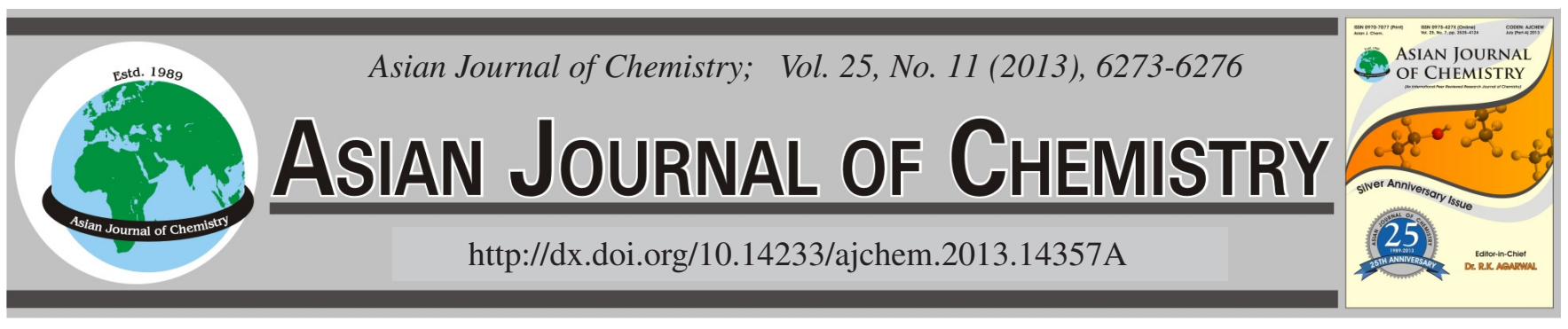

\title{
Fading Spectrophotometric Quantification of Mesna in Commercial Injections with Ferric Salicylate Complex System
}

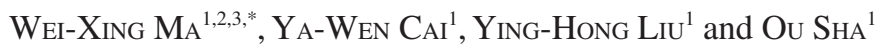

${ }^{1}$ School of Chemical Engineering, Huaihai Institute of Technology, Lianyungang 222005, Jiangsu Province, P.R. China

${ }_{2}^{2}$ Jiangsu-Marine Resources Development Research Institute, Lianyungang 222005, Jiangsu Province, P.R. China

${ }^{3}$ Key Lab of Applied Chemistry, Huaihai Institute of Technology, Lianyungang 222005, Jiangsu Province, P.R. China

*Corresponding author: Tel: +86 518 85895405, E-mail: weixingma650528@163.com; weixingma650528@126.com

\begin{abstract}
A new simple fading spectrophotometric quantification of mesna was developed, which based on the reaction of ferric solution with mesna (2-mercapto ethane sulfonate) to produce ferriferrous ion, whereas result from the red complex with the maximum absorption peak at $530 \mathrm{~nm}$ by the reaction of excess of ferric ion with sodium salicylate. The dependence of the absorbance on acidity, temperature and reaction time was investigated. In the diluted $\mathrm{HCl}$ solution, the decrease value of the absorbance $(\Delta A)$ at $530 \mathrm{~nm}$, due to the presence of mesna was correlated with its concentration. Beer's law was obeyed in a mesna concentration range of 1-30 $\mu \mathrm{g} \mathrm{mL} \mathrm{m}^{-1}$ with good correlation coefficient $(0.9987)$. The proposed method was successfully applied to the quantification of mesna in commercial injections with the recoveries of the range from $99.68 \%$ to $101.0 \%$.
\end{abstract}

Key Words: Quantification, Mesna, Fading spectrophotometry, Injection.

ᄂ - - - - - - - - - - - - - - - - - - - - - - -

\section{INTRODUCTION}

As an important non-toxic thiol compound, the chemical name of mesna is sodium 2-mercaptoethane sulfonate, which prevents hemorrhagic cystitis in patients who receive oxazaphosphorine treatment, such as ifosfamide or cyclophosphamide, by neutralizing the highly reactive urotoxic metabolites of oxazaphosphorines locally in the urine ${ }^{1}$.

Some procedures have been reported in the literature for the quantification of mesna,such as voltammetry ${ }^{2}$, vibrational spectroscopy ${ }^{3}$, solid-phase microextraction GC-MS ${ }^{4}$, flow injection method ${ }^{5}$, HPLC method ${ }^{6-10}$ and spectrophotometry $^{11}$.

Visible spectrophotometric methods have been widely applied to the quantification of organic compounds of pharmaceutical preparations for faster and cheaper than HPLC method and more precise than voltammetry. In this work, a new fading spectrophometric method for the quantification of mesna was developed, which was based on the reaction between mesna and ferric solution, then the colour reaction of excess of ferric ion with sodium salicylate to produce the red complex with the maximum absorption peak at $530 \mathrm{~nm}$. There are no complicated sample separation and extraction steps with satisfactory analytical results in this proposed method.

\section{EXPERIMENTAL}

722-N spectrophotometer (Shanghai Precision and Scientific Instrument Co. Ltd., China).

All the reagents used were of analytical reagent grade and the solutions were prepared with distilled water unless otherwise specified.

A stock solution of mesna $\left(500 \mu \mathrm{g} \mathrm{mL}^{-1}\right)$ was prepared by dissolving $0.1250 \mathrm{~g}$ of mesna in $250 \mathrm{~mL}$ volumetric flask and

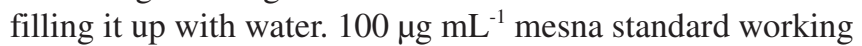
solution was obtained by diluting the stock solution with water. $100 \mu \mathrm{g} \mathrm{mL} \mathrm{m}^{-1}$ ferric solution was prepared by dissolving 0.8640 $\mathrm{g}$ of ferriammonium sulfate in $15 \mathrm{~mL} 4 \mathrm{~mol} \mathrm{~L}^{-1}$ hydrochloric acid solution and diluting the solution to $1000 \mathrm{~mL}$ with water. Sodium salicylate solution was prepared by dissolving $1.0 \mathrm{~g}$ of sodium salicylate in $100 \mathrm{~mL}$ volumetric flask and filling it up with water. $0.1 \mathrm{~mol} \mathrm{~L}^{-1}$ hydrochloric acid solution was employed as reaction medium.

Appropriate amount of the sample solution or standard mesna working solution and $3.50 \mathrm{~mL}$ of $100 \mu \mathrm{g} \mathrm{mL}^{-1}$ ferric solution were transferred into a $10 \mathrm{~mL}$ colourimetric tube. Then the tube was heated $15 \mathrm{~min}$. in $90{ }^{\circ} \mathrm{C}$ water-bath and cooled to room temperature with following water, $1.50 \mathrm{~mL}$ $0.1 \mathrm{~mol} / \mathrm{L}$ hydrochloric acid solution and $2.00 \mathrm{~mL}$ sodium 
salicylate solution were added to the heated then cooled solution, diluted to the mark with water. After lying aside for 15 min at room temperature, the absorbance $A$ of the complex solution was measured with $1 \mathrm{~cm}$ cell at $530 \mathrm{~nm}$. The measurement was repeated in the absence of mesna to obtain the absorbance $A_{0}$ of the reagent blank. The absorbance difference was defined as $\Delta A=A_{0}-A$.

\section{RESULTS AND DISCUSSION}

Absorption spectra: Mesna is sodium 2-mercaptoethanesulfonate and an important thiol compound. As we know, the mercapto or thiol compound can be used as the reducing agent in the redox reaction. So the redox reaction between mesna and ferric solution is used in this work, whereas the excess of ferric ion can react with sodium salicylate solution to produce the red ferric salicylate complex with the absorption peak at $530 \mathrm{~nm}$ in the hydrochloric acid solution medium. The reaction mechanism is as followed in reaction equation (1) and (2):

$2 \mathrm{HSCH}_{2} \mathrm{CH}_{2} \mathrm{SO}_{3} \mathrm{Na}+2 \mathrm{Fe}^{3+}=2 \mathrm{Fe}^{2+}+$

$$
\mathrm{NaO}_{3} \mathrm{SCH}_{2} \mathrm{CH}_{2} \mathrm{~S}-\mathrm{SCH}_{2} \mathrm{CH}_{2} \mathrm{SO}_{3} \mathrm{Na}+2 \mathrm{H}^{+}
$$

ferric ion + salicylate $=$ red ferric salicylate complex $(530 \mathrm{~nm})(2)$

The absorption spectra of the reagent blank and the solution contain of mesna were shown in Fig. 1. From Fig. 1, it was found that the absorbance of the reagent decreased obviously at the presence of mesna. The absorbance difference $(\Delta A)$ reached a maximum at $530 \mathrm{~nm}$. Hence, $530 \mathrm{~nm}$ was selected for further studies.

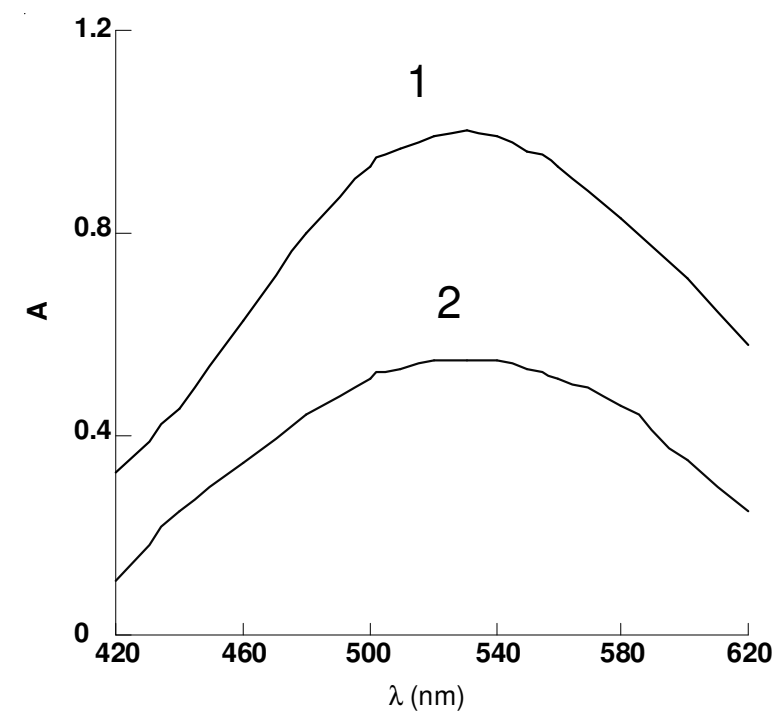

Fig. 1. Absorption spectra: (1) the reagent blank vs. water; (2) the solution containing mesna $v s$. water; [Mesna] $=20 \mu \mathrm{g} \mathrm{mL}$

Effect of heating temperature: At room temperature the redox reaction between mesna and ferric solution is very slow. Thus the heating condition was investigated. It was found that effect of heating temperature on $\Delta A$ in the range of $40-95^{\circ} \mathrm{C}$ for the redox reaction between mesna and ferric solution in Fig. 2. It was seen that $\Delta A$ was almost constant at $80-95^{\circ} \mathrm{C}$. For the reason of simple operation, $90{ }^{\circ} \mathrm{C}$ was chosen as optimum temperature for further study.

Effect of reaction time: The effect of heating time for the redox reaction between mesna and ferric solution was studied. As shown in Fig. 3, mesna reacted with ferric solution within at most $10 \mathrm{~min}$ at $90^{\circ} \mathrm{C}$. The formed red ferric salicylate complex remained steady at least $1 \mathrm{~h}$. Therefore $15 \mathrm{~min}$ of heating time was chosen in the experiments.

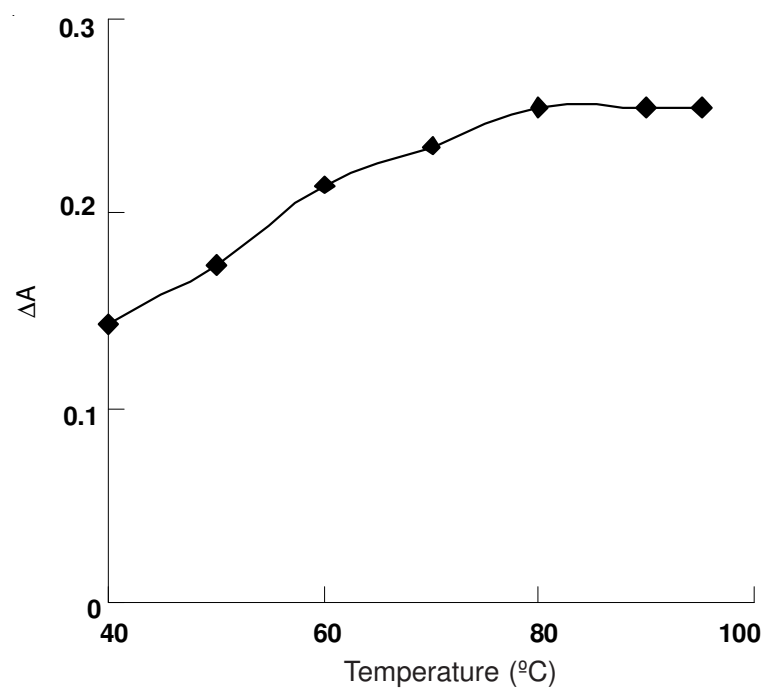

Fig. 2. Effect of heating temperature: [Mesna] $=20 \mu \mathrm{g} \mathrm{mL}^{-1}$

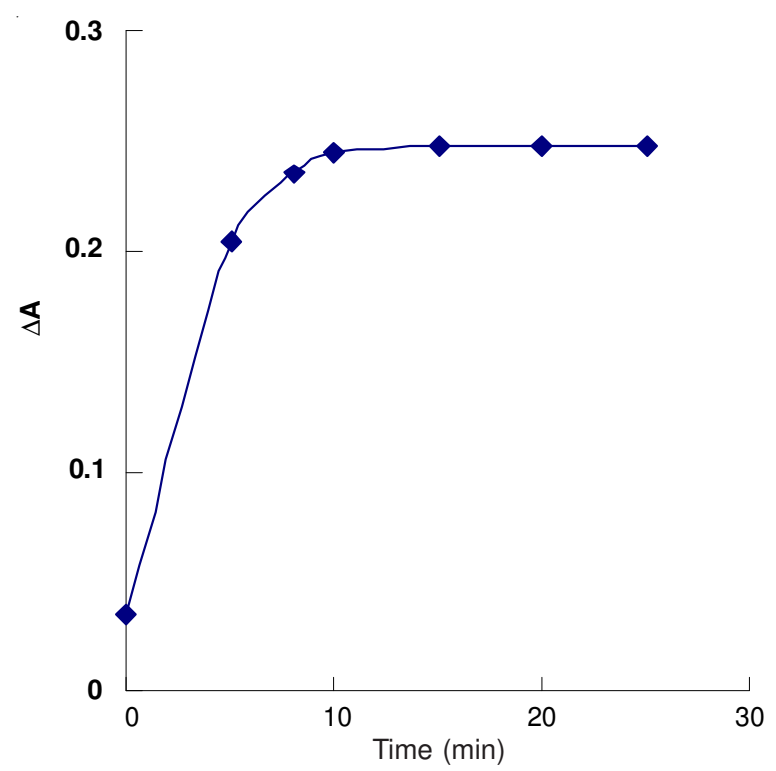

Fig. 3. Effect of heating time: [Mesna] $=20 \mu \mathrm{g} \mathrm{mL}$

Effect of hydrochloric acid solution: The effect of hydrochloric acid solution was investigated on the reaction of excess of ferric with sodium salicylate solution after the reaction of mesna with ferric solution and the results were given in the Fig. 4. It was obvious from Fig. 4, the best volume range of 0.10-2 mL hydrochloric acid solution will give the maximum absorbance $\Delta A$. Therefore $1 \mathrm{~mL} 0.1 \mathrm{~mol} \mathrm{~L}^{-1}$ hydrochloric acid solution was chosen for further studies.

Effect on ferric solution: As the oxidizer of mesna, the concerntration of ferric solution will effect on the absorbance $\Delta A$ of the redox reaction system. From Fig. 5, the ferric concerntration range from 30 to $45 \mu \mathrm{g} \mathrm{mL}^{-1}$ will give the maximum absorbance $\Delta A$ for the system, so $3.50 \mathrm{~mL} 100 \mu \mathrm{g}$ $\mathrm{mL}^{-1}$ ferric solution was chosen in the experiments. 


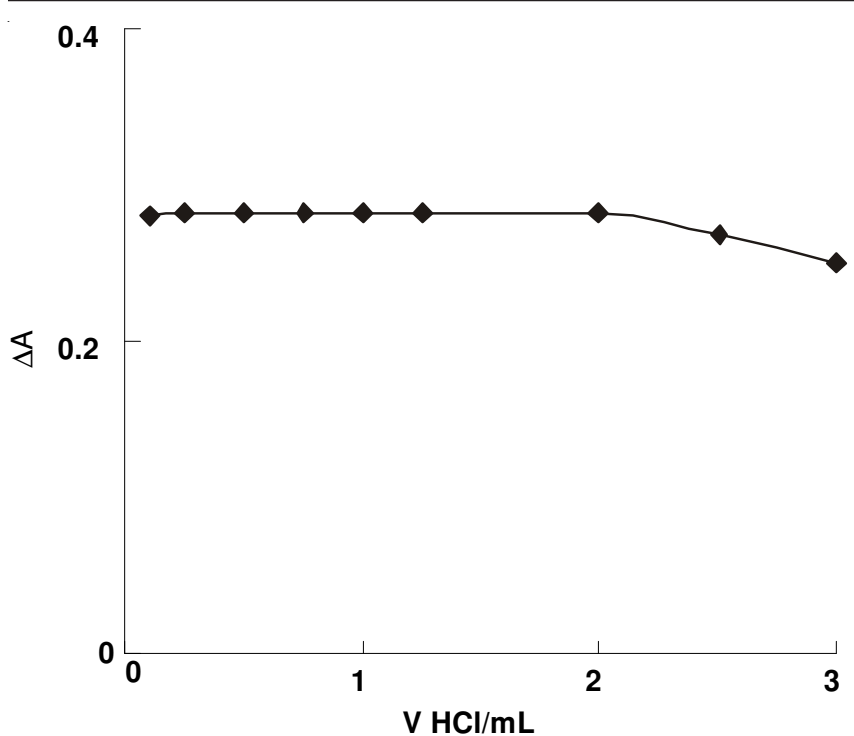

Fig. 4. Effect of volume ammount of hydrochloric acid solution: [Mesna] $=20 \mu \mathrm{g} \mathrm{mL}{ }^{-1}$

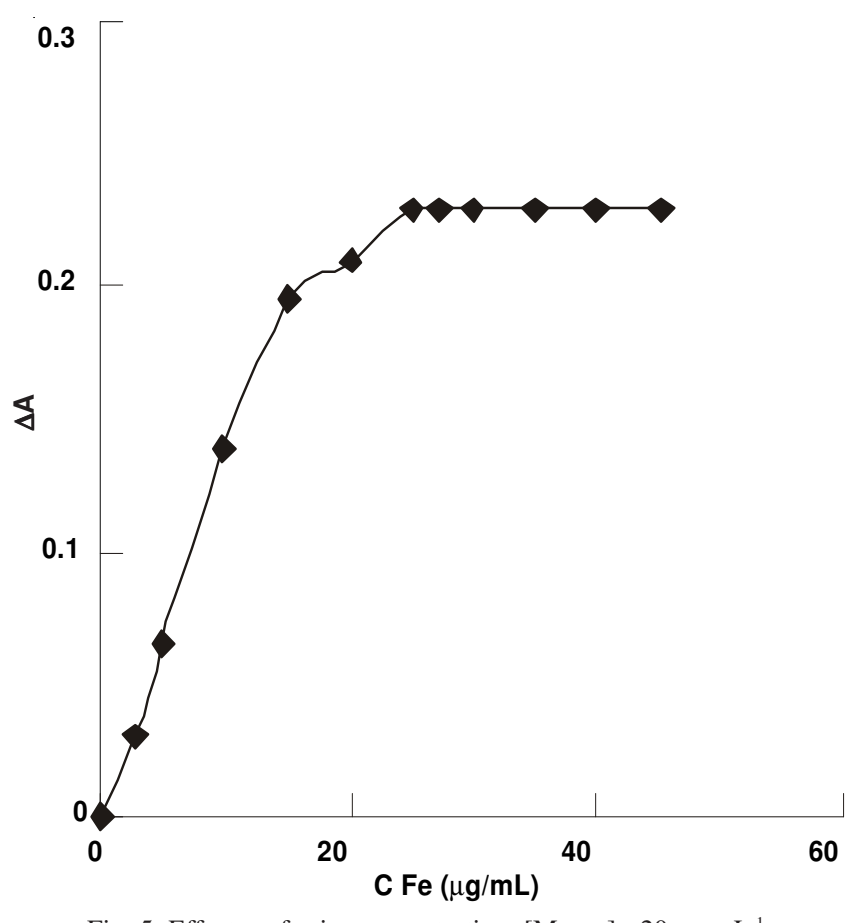

Fig. 5. Effect on ferric concerntration: [Mesna] $=20 \mu \mathrm{g} \mathrm{mL}$

Effect on volume of sodium salicylate solution: As we know, sodium salicylate solution is the colour reagent of ferric ion. From Fig. 6, 2-3.5 mL sodium salicylate solution could give the maximum absorbance $\Delta A$ for the system, so $2.5 \mathrm{~mL}$ sodium salicylate solution was chosen in the experiments.

Calibration graph: A series of standard mesna solutions with different concentration were prepared. Under the chosen optimum experimental conditions, the calibration graph was linear in the range 1-30 $\mu \mathrm{g} \mathrm{mL}^{-1}$ for mesna (Fig. 7). The calibration equation is $\Delta A=0.01114 C+0.0263$ with the regression coefficient $\gamma=0.9987$.

Sample analysis: The proposed method was applied to the quantification of mesna in commercial mesna injections. Five commercial injections, which were obtained from local drug store, were homogeneously mixed and $2.00 \mathrm{~mL}$ mixed

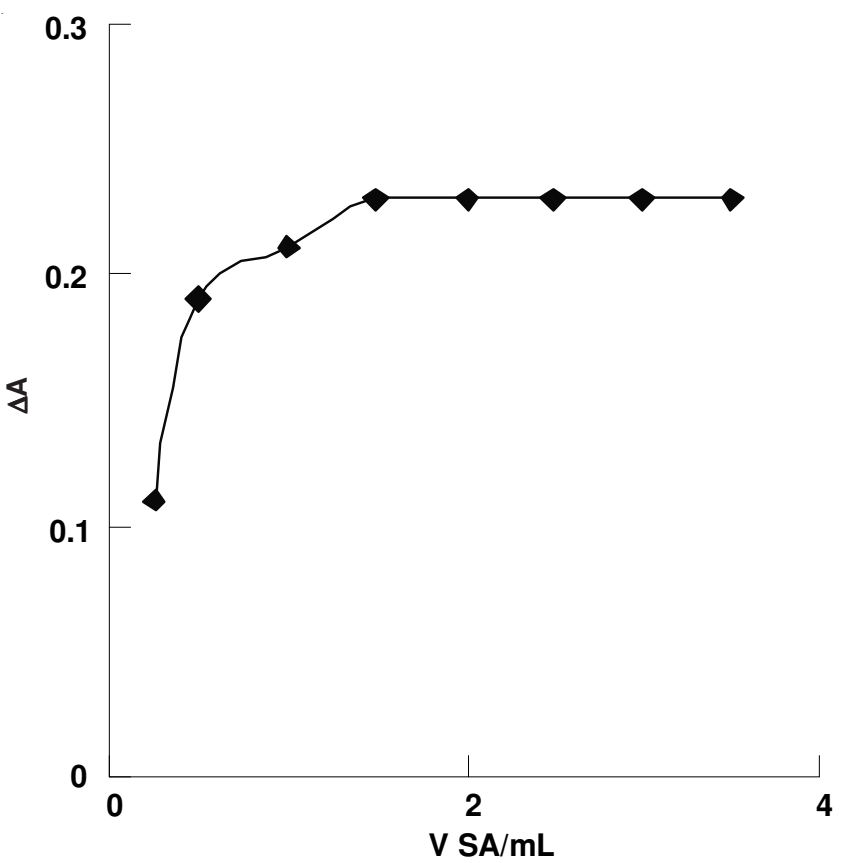

Fig. 6. Effect on volume of sodium salicylate solution: [Mesna] $=20 \mu \mathrm{g} \mathrm{m} \mathrm{m}^{-1}$

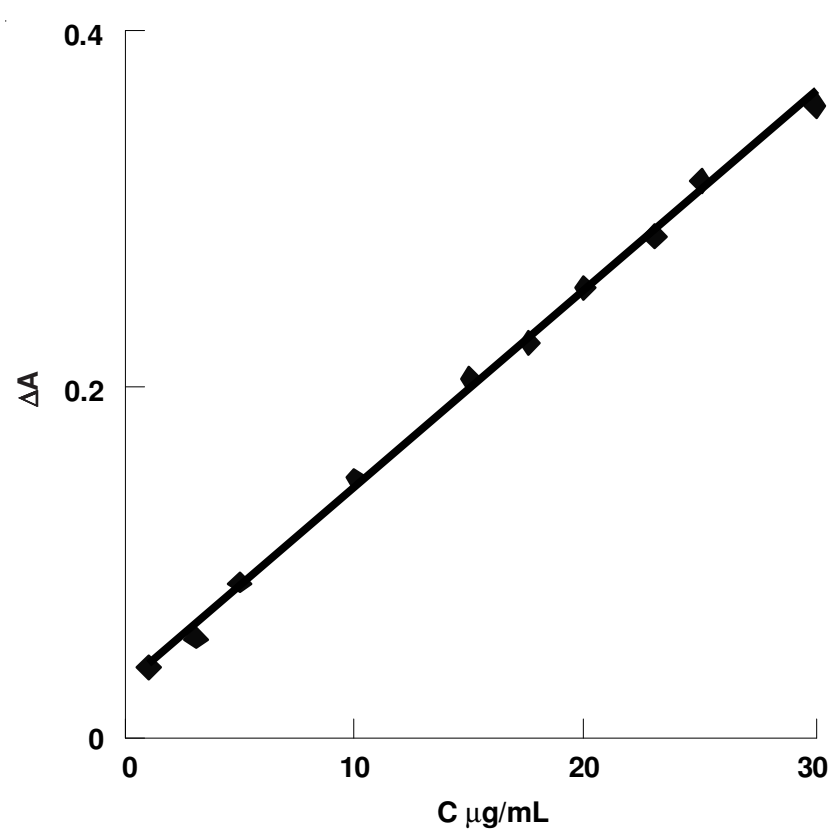

Fig. 7 Calibration graph

solution containing $200 \mathrm{mg}$ of mesna were dissolved in $1000 \mathrm{~mL}$ with water. Then $1 \mathrm{~mL}$ of the diluted solutions were analyzed in five replicate quantifications by the proposed method. Satisfactory results were obtained as shown in Table1. Moreover, to check the validity of the proposed method, the standard addition method was applied by adding mesna to the previously analyzed injections. The recovery was calculated and shown in Table-1.

\section{Conclusion}

A new simple fading spectrophotometric quantification of mesna has been proposed with the advantages of being simple, cheap, accurate and requires minimum equipments and chemicals. It is well suited for routine quality control of the investigated mesna in industrial laboratories. 
TABLE-1

ANALYTICAL RESULTS OF MESNA

\begin{tabular}{|c|c|c|c|c|c|c|}
\hline Injections & $\begin{array}{c}\text { Labeled } \\
\text { amount (mg) }\end{array}$ & $\begin{array}{c}\text { Percentage of labeled } \\
\text { value }^{\mathrm{a}}(\mathrm{w} / \%)\end{array}$ & $\begin{array}{l}\text { RSD } \\
(\%)\end{array}$ & $\begin{array}{c}\text { Added } \\
\left(\mu \mathrm{g} \mathrm{mL}^{-1}\right)\end{array}$ & $\begin{array}{l}\text { Recovered } \\
\left(\mu \mathrm{g} \mathrm{mL}^{-1}\right)\end{array}$ & $\begin{array}{c}\text { Recovery } \\
(\%)\end{array}$ \\
\hline Meian $^{\mathrm{b}}$ & 200 & 99.78 & 1.7 & 50.0 & 49.84 & 99.68 \\
\hline Meian $^{\mathrm{b}}$ & 400 & 100.2 & 2.1 & 50.0 & 50.16 & 101.0 \\
\hline Yidizheng $^{c}$ & 400 & 99.88 & 1.8 & 50.0 & 49.92 & 99.84 \\
\hline
\end{tabular}

\section{ACKNOWLEDGEMENTS}

The authors acknowledged the financial support from the Key Subject Foundation of Huaihai Institute of Technology (U083002) and the Foundation of College Student Innovation Training Program of the Jiangsu Province in 2010. The authors also acknowledged Jiangsu Hengrui Medicine Co. Ltd. for supplying gift sample of mesna.

\section{REFERENCES}

1. A. El-Yazigi, P. Ernst, S. Al-Rawithi, E. Legayada and D.A. Raines, J. Clin. Pharmacol., 37, 618 (1997).

2. J.C.C. Villar, A.C. Garcia, J.M.F. Alvarez and P.T. Blanco, J. Electroanal. Chem., 280, 167 (1990).
3. Y.S. Li, Y. Wang, J.S. Church, F. Garzena, Z. Zhang and D. An, Spectrochim. Acta A, 59, 1791 (2003).

4. S. Takamoto, N. Sakura, M. Yashiki and T. Kojima, J. Chromatogr. B, 791, 365 (2003).

5. L.F.C. Vallvey, M.C.V. Mirón and R.A. Acosta, Talanta, 51, 1155 (2000).

6. C.A. James and H.J. Rogers, J. Chromatogr. B: Biomed. Sci. Appl., 382, 399 (1986).

7. R. Glowacki, D. Gryglik, K. Kusmierek and E. Bald, Talanta, 66, 534 (2005).

8. R. Gowacki, K. Wójcik and E. Bald, J. Chromatogr. A, 914, 29 (2001).

9. R. Gatti, V. Cavrini, P. Roveri and S. Pinzauti, J. Chromatogr. A, 506, 451 (1990).

10. M. Verschraagen, M. Bosma, T.H.U. Zwiers, E. Torun and W.J.F. Van der Vijgh, J. Chromatogr. B, 783, 33 (2003).

11. W.X. Ma, N. Li, O. Sha and Y.H. Liu, Asian J.Chem., 23, 3522 (2011). 